IRA-International Journal of Management \&

Social Sciences

ISSN 2455-2267; Vol.15, Issue 04 (July-September, 2019)

Pg. no. 137-141.

Institute of Research Advances

http://research-advances.org/index.php/RAJMSS

QUARTERLY

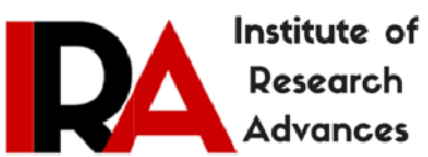

\title{
On the Protection of Unique Modern Architecture in China
}

\section{Xiao Yongliang}

China Institute of Architectural Design, China.

Type of Work: Peer Reviewed.

DOl: http://dx.doi.org/10.21013/jmss.v15.n4.p7

\section{How to cite this paper:}

Yongliang, X. (2019). On the Protection of Unique Modern Architecture in China. IRA-International Journal of Management \& Social Sciences (ISSN 2455-2267), 15(4), 137-141. doi:http://dx.doi.org/10.21013/jmss.v15.n4.p7

\section{(C) Institute of Research Advances.}

\section{(c) EY-NC}

This work is licensed under a Creative Commons Attribution-Non Commercial 4.0 International License subject to a proper citation to the publication source of the work.

Disclaimer: The scholarly papers as reviewed and published by the Institute of Research Advances (IRA) are the views and opinions of their respective authors and are not the views or opinions of the IRA. The IRA disclaims of any harm or loss caused due to the published content to any party.

Institute of Research Advances is an institutional publisher member of Publishers International Linking Association Inc. (PILA-CrossRef), USA. The institute is an institutional signatory to the Budapest Open Access Initiative, Hungary advocating the open-access of scientific and scholarly knowledge. The Institute is a registered content provider under Open Access Initiative Protocol for Metadata Harvesting (OAI-PMH).

The journal is indexed \& included in WorldCat Discovery Service (USA), CrossRef Metadata Search (USA), WorldCat (USA), OCLC (USA), Open J-Gate (India), EZB (Germany) Scilit (Switzerland), Airiti (China), Bielefeld Academic Search Engine (BASE) of Bielefeld University, Germany, PKP Index of Simon Fraser University, Canada. 


\begin{abstract}
Nowadays in China, the action of "Shantytown Renovation" or "Dilapidated-house Transforming" is being undergone. In the process of it, some unique modern buildings are facing a damaged situation. How to deal with the relation between protection and innovation is worth considering. Thus, this paper, from the connotation of architecture and protection, discusses the present feasible approach of protecting those unique modern buildings, based on the meanings and features of the architecture. Meanwhile, the paper attempts to provide a certain reference for our country's planning of "Shantytown Renovation" or "Dilapidated-house Transforming".
\end{abstract}

Keywords: protection; adaptive reuse; unique modern architecture

China is a country with a long history in all kinds of aspects of people's life and architecture is one of these aspects. Since the Opium War in 1840, China has emerged a large number of unique buildings which are not only the beginning of Chinese modern architecture history but also represent the era of a unique combination of Chinese and Western design styles. In recent years, society and the community are getting aware of the concept of protecting buildings. Therefore, how to protect the unique modern architecture attracts more and more attention from both government and building communities (Qin, 2006). This paper, from the connotation of architecture and protection, discusses the present feasible approach of protecting those unique modern buildings, based on the meanings and features of the architecture. Meanwhile, the paper attempts to provide a certain reference for our country's planning of "Shantytown Renovation" or "Dilapidated-house Transforming".

\title{
1. Fundamental Terms
}

1) Architecture and Unique Modern Architecture

As a science, architecture can reflect the nature of age, technical arts, and construction materials. Just as Jundong (2016) said that the value of architecture is not only embodied from the function of a building itself in its usage, but also from the characteristics of technology and arts. As a matter of fact, architecture itself is the deposit of cultural value in its history (Tongshenget al.2011).

In China, the unique modern architecture indicates a very crucial connotation including historical events, revolutionary movements, famous figures, educational reform (Qiang, 2016), etc.

\section{2) Protection's Interpretation}

The styles of China modern buildings are mostly from those of Western countries because, in the old days when those countries built hotels, churches, restaurants, clubs and other business venues and celebrity apartments in China, they did the buildings in their own national styles (Jinhua, 2014). Thus, the present protection and maintenance of that architecture almost adopt the western ways in the aspects of architectural style, frame features, material texture and construction technology and crafts (Qiguo and Bohong, 2014).

\section{3) Classification of Unique Modern Architecture in China}

Though our government carries out protection in a way similar to the western's, there is still an interpretation of the protection today which identifies the unique modern architecture in the different classification which leads to different attitudes to different classes.

According to the different functions of their usage, these buildings are classified into four categories(Hanglinet al.2007): the first category includes office, commercials, residential houses; the second category includes attractions, the third category includes museums, memorials, education bases, and others are the fourth category so that the protection approach theoretically varies different categories.

\section{Analysis of the Protection of Unique Modern Architecture in China \\ 1) Meanings of Protecting Unique Modern Architecture}

If the modern unique architecture has been given effective protection and maintenance, then it will keep a record of the special age and the humanities (Jianqing, 2014). Moreover, according to Zhao (2014), it will reflect the constructive design of the artistic style, the image characteristics and the scientific value of construction techniques in the field of architecture. What's more, it may perfect the role of the city or countryside, which has a very important practical and far-reaching significance in promoting the economy and producing the brand effect of both the city and countryside. (Ying and Guanghan, 2014). 
2) The Approach of the Protection on the Unique Modern Architecture Just as the above section discussed, different categories may be paid different attitudes in protection. Just as some research demonstrated, ....?

Based on these kinds of different architectural protection, it's obvious to find that these approaches have some in common which means nowadays, the most feasible and flexible method refers to the adaptive reuse of the unique architecture.

The adaptive reuse is a kind of protection concept and approach that can be used to balance the protection and reuse of historic buildings (Chunxia and Dan, 2008). In the premise of respecting the authenticity of historical buildings, it gives historical buildings the new use of adapting to the needs of society (Yongyi, 2016). The aim is to prolong the life cycle of the building or to give more designing life cycle of a building to satisfy the needs of the building from society, culture, economy, and technology (Dan, 2016).

It is a cautious way of rebuilding. The adaptive reuse not only can realize the repetitive use of resources, but also can have strong operability in achieving the carrier of the historical and cultural value (Pengxuet al.2014). Thus, the connotation of the adaptive reuse can be demonstrated as follow Error! Reference source not

found. It means the three core parts including the past, present, and future is all interacted by each other which means the application of adaptive reuse can join the architecture's past, present, and future together in its content and significance.

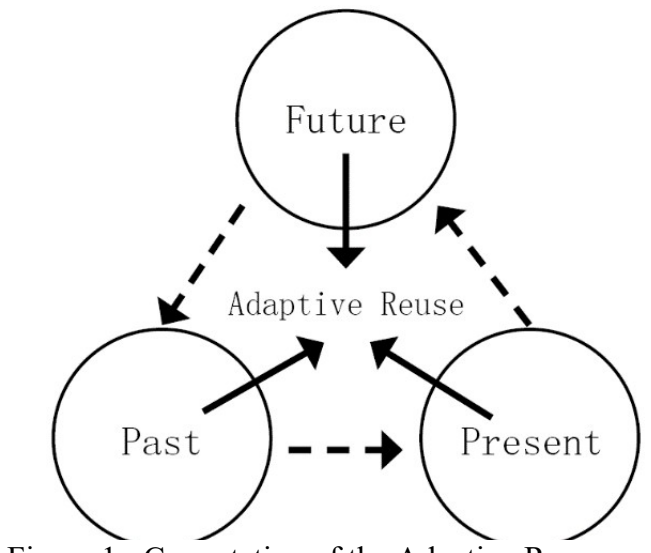

Figure 1 Connotation of the Adaptive Reuse

\section{3) Problems of the Protection on the Unique Modern Architecture}

For a long time in China, the protection of the unique modern buildings have exposed such main problems as 1) people's weak awareness of the value, 2) improper maintenance; 3) less high level of maintenance; 4) overload the usage.

Now, the adaptive reuse is employed, and those problems may be solved, but there are still some new problems such as 1) the standard of the assessment on whether there is a unique modern architecture, 2) the weak awareness of whether the reuse of them is really worthy of protecting, 3) the misunderstanding of the adaptive reuse.

\section{4) Application of the Adaptive Reuse in Protecting the Process}

Applying adaptive reuse includes several steps illustrated as follows:

First of all, it is a need to establish value identification and protection planning for historical buildings. Yan and Yufeng (2017) have analyzed the methodology of energy-saving assessment of historical buildings which is relevant to modern buildings. The highly qualified workers with different knowledge backgrounds should fully understand all the information related to the outstanding buildings from the level of materials, information, and history of the building itself. They also need to analyze and judge the information and structure of the architectural design, the social, economic, cultural and urban environment. Based on the analysis and judgment, an analytical document is then developed to identify which buildings should be strictly protected, or which protected parts may be changed under certain circumstances (Huanyuet al.2015). The document should be open to the public and 
supported by the residents. On this basis, a conservation plan, including management policies, is developed to identify the importance of the site and to link it to the future development of the site.

The second step is to find the right new use or function for historical buildings, as it is the basic prerequisite for subsequent adaptations. The requirement of this new function is that the new function can be compatible with existing buildings and also meet the needs of urban development, and bring fresh vigour to the reconstructed buildings as well.

Finally, the concept of adaptive reuse is embodied in the process of transformation, which requires that the new and old functional space should be a harmonious and symbiotic relationship (Xuewei, 2015). To adapt to the needs of new functions, we should do the following points: 1)The transformation of the building still embodies the building material with the original cultural significance; 2) although the original building part may be changed, in general, the transformation can still be back to its original (Mo, 2015); 3) the impact of the change is slight. Therefore, in the process of transformation, the potential of the existing space should be fully excavated from the existing space structure, technology, streamline organization, spatial scale, materials, form characteristics, and other material conditions to establish a good logical relationship between the new and old space (Ling and Jinqiu, 2015). At the same time, the docking relationship between the deep cultural and humanistic conditions of the old space should be established in such a way as to give the original value and quality to the new building.

\section{Development of the Protection in China}

Nowadays, the use of the adaptive reuse is also considering ecological principle and safety so that the rebuilt architecture can not only agree with the demands of environmental protection and energy conservation but also be widely used in the society (Ning, 2007). Moreover, once there is the accomplishment of the adaptive reuse, the law or act of architecture should be established, linking with the city planning and management.

The adaptive reuse is not only a sustainable environmental protection method but also a possible way to protect modern architecture and make the buildings self-sufficiently survive as well. Moreover, adaptive reuse can help the buildings get rid of specimen-style protection and reintegrate them into people's lives. Therefore, it is an everlasting topic to discuss the adaptive reuse in architectural research.

Although adaptive reuse has been implemented in our country for many years, our government still does not have unified reference standards or related laws to protect the modern building. This will be a further topic for future research.

\section{References}

[1]. Xiao YonglingResearch on the difficulties and solutions of popularization and development of adaptive reuse in China [D] 2017

[2]. Ning, 2007)...

[3]. BAOAN, Z.(2015) Heritage adaptive protection and utilization In Beijing Modern Architectural. MSc, Tianjin University

[4]. CHUNXIA, C. \& DAN, D. (2008), "Research on the Protection and Utilization of Modern Architecture in Chongqing", Chongqing Architecture, No. 12, pp. 05-07.

[5]. DAN, T.(2016) Research on Green Reuse of Old Industrial Buildings in Dalian. MSc, Dalian University of Technology

[6]. HANGLIN, L., CHANGMING, Y., LIANG, L. \& YE, Y. (2007), "Historical and Cultural Heritage Protection and Reuse", Journal of Tianjin University (Social Sciences), Vol. 9 No. 3, pp. 233-237.

[7]. HUAYONG, J. (2015), "The Protection and Development of Historic Architecture", Traditional Chinese Architecture And Gardens, No. 04, pp. 61-64.

[8]. JIANQING, D.(2014) Study on the reuse strategy of the old industrial building In Dongguan. MSc, South China University of Technology

[9]. JUNDONG, Z. (2016), "The protection and reuse of modern architecture", China Real Estate, No. 25, pp. 76-77.

[10]. LING, M. \& JINQIU, S. (2015), "Study on the Trend of Adaptive Reuse of Hong Kong Historic Building Driven by the Collective Memory", Huazhong Architecture, No. 12, pp. 35-40.

[11]. NING, L. (2007), "Protection and utilization of important modern buildings--A case study of Nanjing presidential palace", Urban Development, No. 16, pp. 78-79.

[12]. PENGXU, T., YUN, Z., GUOHUA, H. \& YIFEI, W. (2014), "The Economic Value Realization Mode of Adaptive Reuse of Old Buildings", Journal of Shaoxing University, Vol. 34 No. 10, pp. 14-18.

[13]. QIANG, Z.(2016) Research on Maintenance and Renovation Technology for The Modern Historical BuildingsTaking The Qingdao Navy Club for Example. MArch, Qingdao Technological University

[14]. QIGUO, L. \& BOHONG, Z. (2014), "A Tentative Analysis of Chinese Industrial and Mining Heritages Protection on The Basis of Adaptive Reuse Theory", Industrial Construction, No. 02, pp. 01-04. 
[15]. TONGSHENG, X., CHANGMING, Y. \& QINTAN, D. (2011), "Continuity and Renewal: strategies of Restoration and Reuse of Modern Architectural Heritages", New Architecture, No. 02, pp. 30-32.

[16]. XUEWEI, J.(2015) The Adaptive Reuse Research on Typical Space of the Urban Industrial Heritage-Take Industrial District Regeneration of Shougang for Instance. MArch, Beijing University of Civil Engineering and Architecture

[17]. YING, Q. \& GUANGHAN, L. (2014), "The Renewal and Protection of Residential Houses in Pingyao City", China Ancient City, No. 03, pp. 70-72.

[18]. YUQIAO, F.(2017) The Investigation and Research of Protection and Utilization of Historic Buildings in Jinan Commercial Port Area. MA, Shandong University 